\title{
Organização dos usuários, participação na gestão e controle das organizações sociais $^{1}$
}

\author{
Marianne Nassuno
}

A reforma do aparelho do Estado, conduzida pelo Ministério da Administração e Reforma do Estado (MARE), objetiva a implantação da administração gerencial no governo federal, que tem o foco no cliente como um de seus princípios. Este trabalho discute as possibilidades de implantação da administração voltada para o cliente, mais especificamente, no que diz respeito à participação do usuário na gestão e controle das entidades prestadoras de serviços públicos qualificadas como Organizações Sociais, visando garantir a eficiência e a qualidade.

A participação de usuários na gestão e controle de instituições públicas é um instrumento que pode resolver problemas da relação principal-agente entre políticos e burocratas. Os usuários dos serviços públicos podem auxiliar os políticos na supervisão e garantir a implementação eficiente das políticas por eles definidas, pois detêm informações sobre o desempenho dos burocratas.

Este artigo analisa a relação da participação do usuário com a implementação eficiente de políticas públicas. Não significa, no entanto, que se desconsidere a relevância da definição de políticas para a eficiência e a qualidade da prestação de serviços públicos, nem tampouco que se suponha que a participação do usuário é uma condição suficiente para garantir eficiência e qualidade. A eficiência depende de vários fatores como a flexibilização dos instrumentos de gestão de pessoal e de compras, e da liberação e disponibilização de recursos orçamentários, temas que envolvem o âmbito mais amplo da definição de políticas.

Marianne Nassuno é mestre em Administração pela FGV/SP e especialista em políticas públicas e gestão governamental no Ministério da Administração Federal e Reforma do Estado 
Ademais, a importância da participação não se restringe a questões de eficiência, pois é instrumento de transformação das relações entre o Estado e a sociedade e, portanto, de democratização.

$\mathrm{Na}$ reforma atual, a importância desses aspectos é reconhecida. Segundo seu plano diretor, a reforma do aparelho do Estado está orientada para tornar a administração pública mais eficiente e voltada para a cidadania e prevê a flexibilização de instrumentos de gestão e a liberação global e integral das dotações orçamentárias para as diversas instituições. ${ }^{2}$ Esses temas não serão abordados neste artigo, que se concentra em discutir a participação dos usuários na gestão como forma de garantir a implementação eficiente de políticas públicas.

No projeto das Organizações Sociais, a participação dos usuários na gestão se viabiliza, entre outros meios, pela presença de entidades representativas da sociedade civil no Conselho de Administração das instituições, pressupondo, portanto, a organização dos usuários.

Por essa razão, para discutir a participação do usuário será utilizada a abordagem da "lógica da ação coletiva". Instituições públicas específicas podem ter uma clientela definida (a população de um bairro, por exemplo), havendo incentivos para que a ação coletiva desses usuários se organize e pressione pela melhoria da qualidade dos serviços. Uma vez que os benefícios são concentrados entre os membros dessa comunidade, haveria interesse em arcarem com os custos de organização e participarem da gestão e controle da instituição. Assim, a organização da ação coletiva dos usuários de uma instituição específica pode possibilitar a melhora na qualidade dos serviços públicos, garantindo a implementação adequada das políticas. ${ }^{3}$

$\mathrm{O}$ artigo está dividido em três partes. Na primeira parte, o projeto das Organizações Sociais e os instrumentos previstos para implantar a administração voltada para o cliente são apresentados de forma sucinta. Na segunda parte, a relação entre a participação dos usuários na gestão e controle de instituições públicas e a implementação eficiente de políticas é comentada a partir da abordagem do principal-agente. Na terceira parte, a possibilidade de criação de entidades representativas de interesse de usuários com base na abordagem da "lógica da ação coletiva" é analisada e são discutidos os instrumentos alternativos para viabilizar a participação dos usuários na administração. Nos comentários finais, são resumidas as principais considerações do artigo. 


\section{O projeto das Organizações Sociais}

No modelo conceitual que embasa a atual reforma do aparelho de Estado, consubstanciada no Plano Diretor, são identificadas diversas esferas de atuação do Estado para as quais são previstas entidades com forma de propriedade e instrumentos de gestão diferenciados.

No setor de serviços que não pressupõem o poder de Estado, ${ }^{4}$ mas no qual a presença do Estado se justifica porque envolvem direitos humanos fundamentais ou "economias externas", a prestação dos serviços será descentralizada através de um processo denominado "publicização" para entidades de propriedade pública não-estatal, ${ }^{5}$ regidas pelo direito privado, denominadas Organizações Sociais. ${ }^{6}$

Como Organizações Sociais (OS) poderão ser qualificadas pessoas jurídicas de direito privado, sem fins lucrativos, com objetivos de natureza social que atuem nas áreas de ensino, pesquisa científica e tecnológica, preservação do meio ambiente, cultura e saúde. A organização, assim qualificada, absorverá atividades e serviços prestados por instituições ou órgãos públicos federais, extintos com essa finalidade, recebendo os bens imóveis e o acervo físico, documental e material do órgão extinto.

A absorção pela OS de atividades e serviços prestados por órgãos e instituições da administração pública federal tem como objetivos contribuir para o controle social sobre a oferta de bens e serviços de interesse coletivo custeada pelo Estado e promover a melhoria da eficiência e da qualidade da prestação dos serviços de interesse público, além de contribuir para a redução de custos, para a transparência na alocação dos recursos públicos; possibilitar a redefinição do estilo de atuação do Estado no desempenho de suas funções sociais, com ênfase na descentralização, adoção de modelos gerenciais flexíveis, autonomia de gestão, no controle por resultados e na introdução de indicadores de desempenho e de qualidade na prestação de serviços ao público, conforme o Programa Nacional de Publicização.

A OS terá o Conselho de Administração como órgão de deliberação superior, cuja estruturação será definida pelo seu Estatuto, obedecendo alguns critérios no que diz respeito à sua composição e ao mandato de seus membros, que podem ser natos ou eleitos. O Conselho de Administração deverá ser composto por 20 a $40 \%$ de representantes do Poder Público, 20 a 40\% de membros indicados pelas instituições representativas da sociedade civil, 20 a $40 \%$ de membros eleitos dentre pessoas de notória capacidade profissional 
e reconhecida idoneidade moral e até $10 \%$ de membros indicados ou eleitos na forma estabelecida pelo Estatuto. ${ }^{7}$ A previsão de pluralidade na composição do conselho e de obrigatoriedade de renovação de seus integrantes visa inibir a oligarquização do controle desses conselhos.

As entidades representativas da sociedade civil que participarão do conselho de OS específicas serão definidas pelo Estatuto. Com isso, permite-se a concretização de soluções coerentes com as especificidades do serviço. Pretende-se que essas entidades sejam representantes dos interesses dos usuários.

O conselho terá entre suas competências a definição de objetivos e diretrizes de atuação da entidade, a aprovação da proposta de orçamento e o programa de investimentos, a aprovação de alteração do Estatuto da entidade e a fiscalização do cumprimento das diretrizes e metas definidos para a entidade.

Em resumo, o foco no cliente está explicitado no projeto das OS em quatro dispositivos. O Programa Nacional de Publicização tem por finalidade orientar e coordenar a absorção por OS de atividades e serviços prestados por órgãos e entidades da Administração Pública Federal com, entre outros, o objetivo de contribuir para o controle social sobre a oferta de bens e serviços de interesse coletivo custeada pelo Estado e promover a melhoria da eficiência e da qualidade da prestação dos serviços de interesse público.

Existe a previsão de participação de representantes indicados por entidades da sociedade civil no Conselho de Administração das OS na proporção de 20 a $40 \%$ do total de membros, sendo que este conselho é o órgão de deliberação superior da OS.

As OS deverão, adicionalmente, ter um manual de qualidade, e o contrato de gestão deverá indicar metas específicas relacionadas com a qualidade do produto ou serviço prestado.

$\mathrm{O}$ instrumento para implantar a administração voltada para o cliente, discutido neste artigo, é o que possibilita a participação dos usuários na gestão das Organizações Sociais, com a previsão de presença de entidades representativas da sociedade civil no seu Conselho de Administração.

Os instrumentos previstos para implantar a administração voltada para o cliente possibilitam um controle denominado fire alarm sobre os funcionários da instituição prestadora de serviços públicos, que permite resolver problemas associados à relação principal-agente entre os políticos e os burocratas, discutida a seguir. 


\section{A relação principal-agente}

Num sistema democrático, a prestação dos serviços públicos é delegada pelos políticos eleitos para os burocratas, criando um problema de principal-agente, no sentido de que as políticas implementadas pelos burocratas podem não ser aquelas definidas pelos políticos. ${ }^{8}$ Os burocratas detêm um grau razoável de discricionariedade no desempenho de suas funções — pois é impossível regulamentar sua ação em todas as contingências - e podem ter objetivos próprios, diferentes dos interesses dos cidadãos e dos políticos que os representam. ${ }^{9}$ Adicionalmente, detêm informações sobre o custo e o benefício de suas ações e o monitoramento da realização de suas atividades envolve custos, pois não pode ser realizado diretamente, apenas por meio de resultados (Przeworski, 1996).

Os resultados das atividades dos burocratas públicos, por sua vez, não podem ser medidos por um critério único como o financeiro, ao contrário dos privados, uma vez que o objetivo de suas atividades são múltiplos e não redutíveis a uma só dimensão. Por essa razão, a delegação da implementação de políticas e da prestação de serviços dos políticos para os burocratas gera inevitavelmente um certo nível de ineficiência (Przeworski, 1996).

No entanto, os cidadãos, para os quais os serviços públicos são prestados, têm informações sobre o desempenho dos burocratas na implementação de políticas públicas que podem ser utilizadas pelos políticos para resolver os problemas da relação principal-agente com os burocratas. Com base nas informações dos usuários dos serviços públicos, o principal (político) pode controlar o agente (burocrata) (PRZEWORSKI, 1996).

Desta forma, a participação dos usuários na gestão e controle de instituições específicas é potencialmente um instrumento para resolver problemas da relação principal-agente. Entretanto, pelo projeto das OS não existe garantia de que as instituições representativas da sociedade civil representem de fato os usuários daquela instituição. Mesmo que a participação de usuários no conselho seja regrada explicitamente nos regulamentos que dispõem sobre a qualificação de entidades privadas como Organizações Sociais, não se garante a criação de entidades representativas de usuários de OS específicas para que possam participar do conselho.

Se as possibilidades de criação de entidades representantes de usuários não forem investigadas, corre-se o risco de que entidades, representando interesses outros, como o dos funcionários ou 
dos fornecedores da instituição, participem da gestão da instituição. Neste caso, a previsão da participação dessas entidades no Conselho de Administração não resolveria os problemas da relação principalagente entre políticos e burocratas e a ineficiência deles decorrente, uma vez que para isso são necessárias informações sobre o desempenho dos burocratas fornecidas pelos usuários.

Em resumo, os mecanismos previstos no projeto das OS podem resolver o problema da relação principal-agente entre burocratas e políticos à medida que criam a possibilidade de participação dos usuários na gestão, que potencialmente pode auxiliar os políticos no controle sobre os burocratas. No entanto, é criado um novo problema: qual a garantia de que as entidades da sociedade civil que participam do Conselho de Administração sejam de fato representantes de usuários e não de interesses específicos? ${ }^{10}$ Por essa razão, a questão da organização da ação coletiva dos usuários será discutida a seguir.

\section{Organização dos usuários}

Para se discutir a possibilidade de organização e participação efetiva dos usuários no Conselho de Administração das OS há de se levar em conta transformações ocorridas na estrutura e nos padrões de intermediação de interesses no Brasil, com o surgimento e proliferação de associações.

A partir do final da década de 70 , surgiram novos movimentos sociais, incluindo uma diversidade de manifestações associativas tanto de segmentos da nova classe média quanto de setores populares. Manifestações de massa esporádicas e desestruturadas, mas também formatos mais estruturados de organização para a defesa de interesses ligados a serviços urbanos e a bens de consumo coletivo, formação de grupos em função de atributos como raça, sexo, temas religiosos e para a defesa do meio ambiente fizeram parte desse processo (DINIz e Boschi, 1989).

Segundo Diniz e Boschi (1989), essas manifestações coletivas indicam a formação de novas identidades coletivas, tentando recriar um espaço democrático no nível das relações interpessoais e abrir novos canais de intermediação de interesses e arenas de participação política. Esses movimentos se originaram no processo de enfrentamento do regime autoritário e representaram uma resposta à crise de governabilidade e à descrença na eficácia dos mecanismos de representação para a consecução de políticas e processamento 
de demandas, resultando numa quebra do oligopólio de participação pela via do sistema partidário.

Esses movimentos, entretanto, têm um caráter cíclico devido à natureza tópica e de curto prazo das demandas, "à dificuldade de manter fluxos permanentes de participação e à ausência de vínculos horizontais entre diferentes tipos de movimentos e outros segmentos da sociedade, resultando, portanto, em relativa fragmentação e isolamento" (Diniz e Boschi, 1989:45).

$\mathrm{Na}$ década de 80 , os movimentos se estabeleceram nos bairros, buscando pressionar diretamente as entidades públicas prestadoras de serviços, tendo como resposta a criação de órgãos participativos em alguns setores dos serviços públicos. Nesse processo, os movimentos foram obrigados a negociar, o que possibilitou a reavaliação dos limites e o significado da participação popular. Essa institucionalização da participação foi, no entanto, descontínua: os órgãos colegiados foram esvaziados ou sofreram mudanças que se assemelharam à extinção. Além disso, o diálogo direto com setores da administração pública criou especializações entre os movimentos sociais, não contribuindo para a formação de uma rede de movimentos de várias categorias ${ }^{11}$ (CARdoso, 1995).

A dinâmica de mobilização popular, apresentada anteriormente, pode trazer alguns elementos para se pensar a possibilidade efetiva de organização e participação dos usuários. Segundo STOne (1988), embora o objetivo do esforço coletivo seja alcançar interesses coletivos, as recompensas para a participação podem estar mais associadas à própria participação que aos resultados. Existem períodos em que a dinâmica da mobilização alimenta a si mesma: "groups set examples for other groups; they inspire each other with heroism; they help each other; and the successes of one group motivate others" (STONE, 1988:174).

STONE (1988) indica que a mobilização é viabilizada por outros elementos que não a escolha racional dos agentes, incorporando fatores como a influência de parentes, amigos, professores e a cultura para explicar a organização da ação coletiva, bem como, salientando a importância da percepção dos problemas e da forma como são apresentados, dado o caráter simbólico das questões políticas. A autora, no entanto, dá menor importância aos custos da participação, que devem ser levados em consideração na avaliação da real possibilidade de organização e participação dos usuários.

Embora a dinâmica social verificada no Brasil forneça alguns indícios de que tende a se tornar um movimento auto-alimentado nos termos de Stone, os autores analisados ressalvam a relativa fragmentação e descontinuidade da experiência brasileira, o que 
justifica a preocupação com relação às possibilidades reais de constituição de entidades representativas de interesses de usuários.

Adicionalmente, na avaliação das possibilidades de participação efetiva dos usuários na gestão é preciso considerar que a saúde - uma das áreas onde as OS podem atuar — vem sofrendo um processo denominado "universalização excludente". ${ }^{12}$

Este processo teve início com a ampliação do acesso aos serviços públicos de saúde, mediante a incorporação de trabalhadores rurais, autônomos e domésticas como beneficiários na década de 70, culminando com a abertura do acesso ao sistema público de saúde a toda a população, independentemente de qualquer critério ocupacional ou rendimento na década de 80 . Essa universalização não foi acompanhada de uma expansão correspondente da rede de serviços, resultando na redução da qualidade dos serviços, demora no atendimento, que funcionaram como mecanismos de racionamento que acomodaram a deman-da ampliada à oferta em lento crescimento (FAVEret e Oliveira, 1990).

Os segmentos médios e altos da população reduziram suas expectativas em relação ao atendimento público de saúde, passando a utilizar os serviços do subsistema privado, cujo desenvolvimento foi incentivado. ${ }^{13} \mathrm{O}$ sistema se acomodou porque a expulsão provocada pelo racionamento no subsistema público foi compensada pela absorção destes segmentos no subsistema privado.

Setores sociais médios e empregados das grandes empresas privadas deixaram de considerar o sistema público de saúde como seu referencial efetivo de atendimento. Com isso, perdeu-se em termos de composição política na defesa das melhorias e ampliação do setor público de saúde, no que diz respeito à capacidade de formação de opinião pública dos setores médios e o potencial mobilizador dos grandes sindicatos de trabalhadores (FAVERET e OliveirA, 1990).

Assim, pelo processo de "universalização excludente", as camadas da população que não têm recursos para adquirirem serviços privados tornaram-se o principal usuário do serviço público de saúde que, ao contrário das classes médias e altas, têm um menor grau de mobilização.

Em suma, o argumento de Stone (1988) indica que a mobilização popular pode constituir-se num processo auto-alimentado. No entanto, esse autor dá menor importância aos custos de organização e participação e a análise do processo brasileiro mostra uma tendência de fragmentação e descontinuidade. Como agravante, ocorreu o processo de "universalização excludente" que retirou a saúde - uma das atividades passíveis de serem transferidas para 
OS — da pauta de reivindicações dos segmentos mais mobilizados da população. Esse contexto mostra que o surgimento de entidades de representação de interesses de usuários para participar dos Conselhos de Administração das OS não está dado. Por essa razão, julga-se necessário discutir a questão com mais detalhe utilizando a abordagem da "lógica da ação coletiva" e pensar mecanismos alternativos de participação no usuário na gestão.

A "lógica da ação coletiva" representa uma abordagem importante para se refletir sobre as possibilidades de organização dos usuários porque incorpora a noção de que essa organização envolve custos. Os custos de organização estão relacionados com a comunicação e com a negociação de um acordo entre os membros do grupo, com o monitoramento das suas ações e com a manutenção de uma estrutura formal de organização, e aumenta com a elevação do número de participantes (Olson, 1971).

Olson (1971) associa a organização da ação coletiva com a necessidade de interação estratégica entre os membros de um grupo para a obtenção de um bem coletivo. Levar em conta ação dos outros membros do grupo para decidir sua própria ação depende de fatores como a quantidade de benefícios e o tamanho do grupo. A partir desses elementos, especifica as condições nas quais a organização é necessária para a obtenção de bens coletivos.

No menor tipo de grupo não existe necessidade de cooperação para que o bem seja produzido, porque os membros detêm uma parte tão grande do total dos benefícios que julgam valer a pena garantir a provisão do bem mesmo que tenham de arcar com a totalidade dos custos. Em qualquer grupo maior que esse, nenhum bem coletivo poderá ser obtido sem organização.

Existem três fatores que impedem os grupos grandes de alcançar seus interesses. Quanto maior o grupo, menor será a recompensa individual pela participação de cada membro, menor o interesse de um membro individual ou parte do grupo arcar com a totalidade dos custos para a produção do bem e maiores os custos de organização.

Os grupos grandes são denominados latentes e se distinguem pelo fato de que os membros do grupo são indiferentes se um membro participa ou não na provisão do bem e, por essa razão, ninguém tem razões para reagir. Como um indivíduo num grupo latente não pode fazer uma contribuição perceptível para a produção do bem, nenhum membro irá reagir se os demais não participarem, não havendo incentivo para a cooperação. 
Em grupos grandes, a organização da ação coletiva é difícil, mesmo que o bem coletivo seja valorizado, porque não existem incentivos para que os indivíduos trabalhem na organização ou arquem com seus custos. Apenas incentivos seletivos podem estimular um indivíduo racional a atuar para o grupo.

WiLSON (1980) relaciona a mobilização política com os efeitos produzidos pelas políticas, que podem envolver benefícios ou custos. Assume que as pessoas tendem a organizar-se e reivindicar mais por algo que as afeta intensamente do que por algo que as afeta fracamente. Nesse sentido, os efeitos das políticas podem ser concentrados ou difusos.

O grau de concentração do efeito de uma política depende do número de pessoas sobre a qual ela incide e de quanto a vida de cada indivíduo é afetada pela política. As políticas cujos efeitos sejam concentrados incentivam a mobilização política, enquanto que a difusão de efeitos inibe a organização. Dessa forma, quando uma política gera efeitos diferentes sobre grupos diferentes, aqueles com interesses concentrados ou sobre os quais os custos incidem de forma concentrada têm maiores possibilidades de organizarem-se, seja para apoiar seja para combater a política.

Com base na "lógica da ação coletiva", a primeira questão a ser pesquisada para identificação das possibilidades de organização dos usuários refere-se ao conhecimento da clientela da instituição, seu tamanho e o grau de dispersão dos custos de organização ou dos benefícios da melhora dos serviços prestados. Para a avaliação desses fatores é necessário um estudo mais aprofundado das diversas atividades a serem transferidas para as OS. Neste trabalho será feito apenas um breve esboço para indicar as diferenças existentes entre duas instituições passíveis de serem transformadas em OS: as escolas técnicas e os hospitais.

$\mathrm{Na}$ área de educação, os clientes das escolas técnicas são os alunos e as empresas que necessitam de mão-de-obra especializada, formada pela escola. Na saúde, a clientela dos hospitais tende a ser a população de baixa renda e aqueles transferidos pelos níveis primário e secundário para tratamentos especializados. Dessas duas entidades, a organização dos usuários das escolas técnicas tem maiores chances de ocorrer. No caso dos hospitais, corre-se o risco de que os interesses que se organizam não sejam aqueles dos usuários - porque estes constituem um grupo latente e os benefícios da melhoria da prestação de serviços são difusos - em contraposição aos fornecedores e funcionários, que representam um grupo menor, com interesses concentrados, não necessariamente relacionados com a qualidade do serviço. 
Como o grau de dispersão da clientela das instituições passíveis de serem qualificadas como OS é diferenciado, torna-se necessária a criação de mecanismos diferentes para viabilizar a participação dos usuários na gestão. E, dado que a lei que qualifica as instituições como OS tem que ser genérica para possibilitar a inclusão das diversas áreas, esses mecanismos diferenciados devem estar contemplados em regulamentos específicos para cada uma delas, por exemplo, no seu estatuto.

Em suma, as áreas de atuação das OS são diversificadas e com clientelas de diferentes características no que diz respeito ao seu tamanho e ao grau de concentração dos benefícios, exigindo uma análise mais detalhada dessas áreas e sua respectiva clientela. Com base na "lógica da ação coletiva" não existem garantias de que entidades representantes de usuários participem do Conselho de Administração das OS, se o único instrumento previsto para implementar a participação seja a previsão da presença de representantes de entidades da sociedade civil nesse conselho. A fragilidade do instrumento previsto é reforçada pelo fato de que os segmentos mais mobilizados da população não terem na pauta de reivindicações uma das áreas nas quais essas entidades irão atuar: a saúde. Por outro lado, grupos outros - fornecedores, funcionários que não os diretamente relacionados com os interesses dos usuários podem tender a se organizar para participar da gestão dessas entidades devido ao fato de constituírem grupos menores com interesses concentrados.

Adicionalmente aos problemas de organização dos usuários, existem custos de participação para as entidades de usuários atuarem no Conselho de Administração das OS. Estes custos podem ser subdivididos em três: custos relacionados com a obtenção de informações que subsidiam a ação dos grupos; custos de oportunidade, à medida que tomar parte numa atividade significa deixar de fazer outra coisa e custos de fracasso, relacionados com os riscos de perseguição e discriminação dos participantes, com a frustração decorrente de experiências malsucedidas e com a desconfiança de eventual manipulação (Brasileiro citado por CunILl, 1991:239 e 240). A participação implica, portanto, uso de recursos diversos e de tempo, além de alta motivação e eventualmente a necessidade de conhecimentos especiais, ou seja, existem razões pelas quais os usuários podem recusar-se a participar (CunILL, 1991).

Assim, levando-se em conta as dificuldades da organização dos usuários e os custos participação, para se viabilizar de fato a participação dos usuários na gestão das OS é necessário realizar, em primeiro lugar, um mapeamento das entidades passíveis de serem 
qualificadas em OS e de sua clientela. Se esta constituir um grupo grande e disperso, incentivos seletivos serão necessários para promover sua organização. O problema da utilização de incentivos seletivos é que podem agravar a fragmentação e especialização da participação, gerando uma relação corporativa com as instituições. Por essa razão, mecanismos que prescindam da organização da ação coletiva dos usuários podem ser mais interessantes.

Como exemplo desses mecanismos, pode ser citado o ombudsman. Suas funções são geralmente assumidas por um servidor de alto nível, encarregado de zelar pelo bom funcionamento da administração pública, sobretudo, mediante investigação de queixas individuais dos usuários. Sua atuação é independente e implica isenção política. A rigor, não tem poderes, apenas atribuições e certos direitos a elas inerentes, como os de solicitar informações e requisitar documentos às repartições compreendidas em sua jurisdição e fiscalizá-las. Mesmo depois de apreciada a queixa e apurada sua procedência, não lhe cabe rever decisões ou tomar diretamente qualquer medida corretiva. No máximo sugere ou recomenda alguma providência (Leite, C.B. e C.Z. Monteiro, 1971).

Uma vez que o ombudsman não tem poderes, é preciso suplementar esse mecanismo de recebimento e análise de queixas dos usuários com incentivos e penalidades aos funcionários e dirigentes com base no grau de satisfação do cliente, informações que podem ser obtidas com a adoção de um programa de qualidade, previsto no projeto das OS.

\section{Comentários finais}

O projeto das Organizações Sociais prevê um mecanismo importante - a participação dos usuários na gestão e controle das instituições - para resolver o problema da relação principal-agente entre políticos e burocratas. No entanto, esse mecanismo cria uma nova dificuldade que é como garantir que as entidades de usuários se organizem e participem na gestão das OS. Se entidades que agreguem interesses outros que não os dos usuários participarem da administração da instituição, os problemas de implementação de políticas públicas associados ao controle dos políticos sobre os burocratas podem não ser resolvidos.

A mobilização de grupos sociais, verificada a partir da década de 70, apresenta um dinamismo que pode induzir à criação desses grupos. Entretanto, esse movimento mobilizador vem sendo fragmentado e descontínuo. Ademais, a pauta de reivindicações dos 
segmentos mais ativos da sociedade deixou de contemplar a questão da saúde — uma das áreas de atuação das OS — em decorrência do processo de "universalização excludente".

A abordagem da "lógica da ação coletiva" fornece outros elementos para discutir a possibilidade de organização e participação dos usuários ao incorporar a noção de que existem custos associados à organização. Caso os grupos sejam grandes e os benefícios ou custos dispersos, não existem incentivos para a organização da ação coletiva dos usuários.

Nesse caso, torna-se necessário criar incentivos seletivos para viabilizar a organização dos usuários ou mecanismos que prescindam dessa organização. Como exemplo do último caso, cita-se o ombudsman, embora a utilização desse instrumento exija criação de incentivos adicionais a funcionários e dirigentes.

De qualquer forma, os mecanismos de participação dos usuários na gestão das OS vão depender de sua área de atuação e das especificidades de sua clientela. Isso indica a necessidade de mapeamento prévio das instituições e de definição de uma tipologia a partir desses dois fatores para o desenho dos instrumentos adequados.

\section{Notas}

1 Este artigo é a versão revisada do trabalho "Comentários sobre a Participação dos Usuários nas Organizações Sociais" para a Escola Nacional de Administração Pública, desenvolvido na fase aplicada do curso de formação de Especialistas em Políticas Públicas e Gestão Governamental. A autora agradece ao professor Marcus André Mello pela orientação.

2 A respeito desses temas, ver FerRARezi e outros (1996).

3 Geddes (1994) utiliza-se da abordagem da "lógica da ação coletiva" para realizar outro tipo de análise sobre reformas administrativas. Segundo a autora, uma reforma da administração pública global — do tipo transição do sistema de patronagem para o sistema de mérito - não pode ser explicada pela pressão dos cidadãos. Embora propicie uma melhora dos serviços públicos, que é de seu interesse, como esses interesses são difusos, não existem incentivos para que se organizem e pressionem os políticos. A reforma só pode então ser viabilizada quando atende aos interesses dos políticos, numa determinada composição de forças no Legislativo. Supondo que existam eleitores que votem de acordo com sua preferência pelo programa dos partidos e que esses eleitores sejam favoráveis à reforma, os partidos decidirão seus votos contra ou a favor da reforma, comparando os votos que obtêm com a manutenção da patronagem 
com os votos que obteriam se fossem à favor da reforma. Os ganhos de um partido com a manutenção da patronagem representam a diferença entre os votos que o partido obtém com o uso da patronagem e os votos que o outro partido obtém com o uso da patronagem. A magnitude do ganho líquido de cada partido com a manutenção da patronagem está relacionada com a distribuição de recursos de patronagem entre os partidos. Esta depende de fatores como o presidente ser do partido no governo atual ou anteriores, do número de cadeiras ocupadas pelo partido na legislatura atual ou anteriores e se os partidos são ou não "mobilizados internamente.

4 Esse poder, denominado extroverso, é detido unicamente pelo Estado e referese ao "poder de constituir unilateralmente obrigações para terceiros, com extravasamento dos seus próprios limites" (Plano Diretor, 1995: 51).

5 Segundo o Plano Diretor, a propriedade pública não-estatal é uma terceira forma de propriedade além das tradicionais pública e privada, constituída por organizações sem fins lucrativos, que não são propriedade de nenhum indivíduo ou grupo, estando diretamente orientadas para o atendimento do interesse público.

6 Para o setor que define as leis e as políticas públicas, bem como para o setor em que são prestados serviços exclusivos de Estado, estão previstas entidades de propriedade pública, o Núcleo Estratégico e as Agências, respectivamente. A produção de bens e serviços para o mercado voltada para o lucro será descentralizada para entidades de propriedade privada através do processo de privatização. O Plano Diretor propõe, assim, uma redefinição do papel do Estado que deve atuar como promotor e regulador do desenvolvimento econômico e não mais como provedor direto de bens e serviços.

7 Os membros eleitos ou indicados terão mandato de quatro anos, que pode ser prorrogado. Os membros natos serão indicados ou substituídos a qualquer tempo.

8 Existem, adicionalmente, problemas de relação principal-agente entre políticos e cidadãos, pois os políticos podem definir políticas diferentes daquelas preferidas pelos cidadãos que os elegeram. A respeito da relação principal-agente entre os políticos e os cidadãos e alguns mecanismos para resolver os problemas dela decorrentes, ver Przeworski e Stokes (1996) e Przeworski (1996).

9 Podem querer maximizar sua autonomia ou garantir seu emprego, favorecer amigos e parentes ou aumentar os orçamentos que controlam (Niskanen citado por PrZeworski, 1996: 16).

10 Caso as entidades da sociedade civil sejam de fato representantes de usuários, surge ainda uma outra questão que é como tornar a sua participação efetiva, o que depende da regra para a tomada de decisões. Esse tema, no entanto, não será discutido neste trabalho.

${ }^{11}$ Adicionalmente, a especialização das reivindicações foi aprofundada com o período constituinte, na medida que estimulou a criação de lobbies especializados (CARDoso, 1995).

${ }^{12}$ Agradeço a Vinícius Carvalho Pinheiro por mencionar este aspecto.

${ }^{13} \mathrm{~A}$ partir de 1964 , dentro do modelo médico-assistencial, privilegiou-se a subcontratação de serviços por produtores privados, comprimindo a participação dos agentes públicos. Adicionalmente, as linhas de financiamento à saúde foram orientadas para agentes privados, visando à sua expansão e modernização. Na década de 80 , surgiram e proliferaram-se diversas inovações financeiras viabilizadoras do acesso de amplas camadas da população ao subsistema privado como os planos de saúde individualmente contratados, planos de seguro em grupo com participação financeira das empresas privadas e as caixas próprias das empresas estatais (FAVEREt e Oliveira, 1990). 


\section{Referências bibliográficas}

Brasil, Câmara da Reforma do Estado (1995). Plano Diretor do Aparelho de Reforma de Estado. Brasília.

CARdoso, R.C.L. (1995). Mudança sociocultural e participação política nos anos 80. In Sola, L. e L.M. Paulani (orgs.): Lições da década de 80. São Paulo: Universidade de São Paulo.

Cunill, N. (1991). Participación Ciudadana. Caracas: CLAD.

Diniz, E. e R.R. Boschi (1989): A consolidação democrática no Brasil: atores políticos, processos sociais e intermediação de interesses. In: Dinız, E., R.R. Boschi e R. Lessa: Modernização e consolidação democrática no Brasil: dilemas da Nova República. São Paulo: Revista dos Tribunais

Faveret Filho, P. e P.J. de Oliveira (1990). A universalização excludente: reflexões sobre as tendências do sistema de saúde. Planejamento e políticas públicas, n.3, junho.

Ferrarezi, E.R., K. Freiras, M.C.T. Esperança, M.M. Ramos e M. Nassuno (1996). Flexibilização da administração indireta: desafios da reforma. Trabalho apresentado na fase aplicada do curso de especialistas em políticas públicas e gestão governamental. Brasília.

GedDes, B. (1994). Politician's Dilemma. Building State Capacity in Latin America. University of California Press.

Leite, C.B. E C.Z. Monteiro (1971). O ombudsman ganha terreno. Revista do Serviço Público v. 106, n. 2, maio-agosto.

MAre (1996a). Projeto Organizações Sociais. Brasília.

. (1996b). Minuta do decreto que institui o Programa Nacional de Publicização e dá outras providências. Brasília.

Olson, M. (1971). A theory of groups and organizations. In: The logic of collective acion: public goods and the teory of groups. Cambridge University Press.

Przeworski, A. (1996). On the Design of the State: A principal-agent perspective. paper apresentado no Seminário A Reforma do Estado na América Latina e no Caribe: rumo a uma administração pública gerencial. Brasília.

Przeworski, A. e S.C. Stokes (1996). Citizen Information and government accountability: What must citizens know to control governments. Versão revisada de paper apresentado no encontro anual da American Political Association.

STONE, D. (1988). Interests in policy paradox and political reason. Harper Collins. Wilson, J. (1980). The Politics of Regulation. Basic Books. 


\section{Resumo Resúmen Abstract}

\section{Organização dos usuários, participação na gestão e controle das organizações sociais \\ Marianne Nassuno}

O artigo discute a participação dos usuários na gestão das Organizações Sociais, prevista num projeto da reforma do aparelho de Estado atualmente em curso. A participação dos usuários na gestão das instituições públicas é um instrumento que pode resolver problemas da relação principal-agente, garantindo a implementação eficiente das políticas. No projeto das Organizações Sociais, essa participação é viabilizada, entre outros meios, pela presença de entidades representativas da sociedade civil no Conselho de Administração da instituição, pressupondo, portanto, a organização dos usuários. Por essa razão, no artigo são analisadas as possibilidades de organização dos usuários com base na abordagem da "lógica da ação coletiva".

\section{La dinámica de la organización de los usuarios para participación en la} gestión y control de las "Organizações Sociais"

\section{Marianne Nassuno}

El actual proyecto de reforma de la administración pública federal de Brasil prevee la creación de Organizaciones Sociales, com participación de los usuários de los servicios en consejos de gestión de estas instituciones. Este mecanismo puede ser una solución para el problema del principal-agent, garantizando la implementación eficiente de las políticas públicas. Todavia, para viabilizar la participación en la gestión es necesária la organización de los ciudadanos. Este artículo versa sobre las posibilidades de organización y los problemas ocasionados por la lógica de la acción colectiva involucrados en este proceso.

\section{Consumer's participation in the management and oversight of the “Organizações Sociais" \\ Marianne Nassuno}

The "Organizações Sociais" project - part of the present administrative reform of the federal government in Brazil - includes the prevision of popular participation in the administrative councils of parastatal agencies aiming to improve the quality of public services in specific sectors. The article analyses the institutional arrangements for implementation of citizen's monitoring of the bureaucracy using the "collective action logic" approach. The instrument may or may not be effective to solve the principal-agent problems between politicians and bureaucrats in the implementation of public policies depending on how large is the group of the institution's clients and how concentrated are the benefits deriving from its actions.
Revista do

Serviço

Público

Ano 48

Número 1

Jan-Abr 1997

Marianne

Nassuno é mestre em Administração pela FGV/SP e especialista em políticas públicas e gestão governamental no Ministério da Administração Federal e Reforma do Estado 